\title{
Assessing Spanish HSR network utility for same-day tourism
}

\author{
Évaluation de l'utilité du réseau TGV espagnol pour le tourisme d'un jour
}

\author{
José María Coronado · Maddi Garmendia · Amparo Moyano · José María Ureña
}

Received $1^{\text {st }}$ October 2012; accepted 17 May 2013

(C) IFSTTAR et Éditions NecPlus 2013

\begin{abstract}
This paper presents a measurement of the utility of the High-Speed Train (HST) connection between the HST cities in Spain for one-day tourism trips. Higher utility equates to more available time at destination and lower travel time and cost.

Situations are very different for the more than 20 cities considered which are part of the HST network. As all the lines converge into Madrid, the other cities are accessible for tourism trips from there. In contrast, useful connections are not available to some intermediate HST cities because of low frequencies and inadequate timetables.

Our methodology is based on Time Geography principles and allows for comparison of the utility of the HST for the various cities. This utility may be different for other travel purposes or durations.
\end{abstract}

Keywords High Speed train · Spain · Time geography · Tourism · Utility

\footnotetext{
José María Coronado $(\triangle)$

Department of Civil Engineering and City and Regional Planning, University of Castilla-La Mancha Av. Camilo José Cela s/n, 13071, Ciudad Real, Spain

e-mail : josemaria.coronado@uclm.es
}

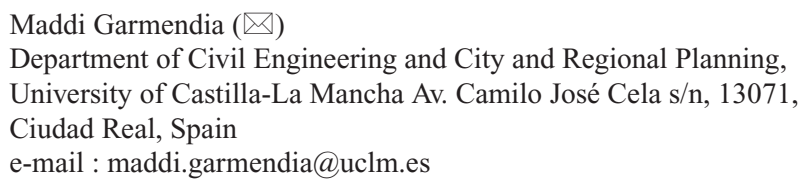

Résumé Cet article propose une évaluation de l'utilité des connexions TGV en Espagne pour des excursions touristiques d'une journée. L'utilité mesurée est fonction du temps disponible à chaque destination, des temps de voyage et des coûts.

Le réseau TGV recouvre des situations très différentes pour les 20 villes considérées. L'accessibilité de Madrid vers les autres villes est assurée pour ce type de voyage, puisque la capitale est la ville la plus favorisée par le réseau radio-centrique et par des fréquences élevées. Au contraire, les connexions aux petites villes intermédiaires sont moins utiles en raison de fréquences faibles.

La méthodologie, basée sur les fondements de la géographie du temps, permet de comparer l'utilité du TGV pour chacune des villes considérées. Cette utilité est différente en fonction du but du voyage ou de sa durée.

Mots clés train à grande vitesse - Espagne - géographie du temps · tourisme - utilité

\section{Introduction}

For the last 20 years, the high-speed rail (HSR) network in Spain has expanded to encompass over twenty stations on six main lines (Fig. 1). The Paris-Lyon HSR line was used as a reference to design the first Spanish high-speed line between Madrid and Seville (471 km apart) in April 1992. A few months later, in October 1992, the passenger load was unbalanced because many passengers from the intermediate medium-sized cities of Ciudad Real and Puertollano used AVE services to travel to Madrid. Thus, trains travelling between Ciudad Real and Seville were half empty. To address this problem, RENFE created a new service called AVE Lanzadera. This HSR service between Madrid, Ciudad Real and Puertollano generated a new type of shuttle service - the regional HST - a combination of high-performance regional train and long-distance suburban train [1]. This model has been adopted in other countries 


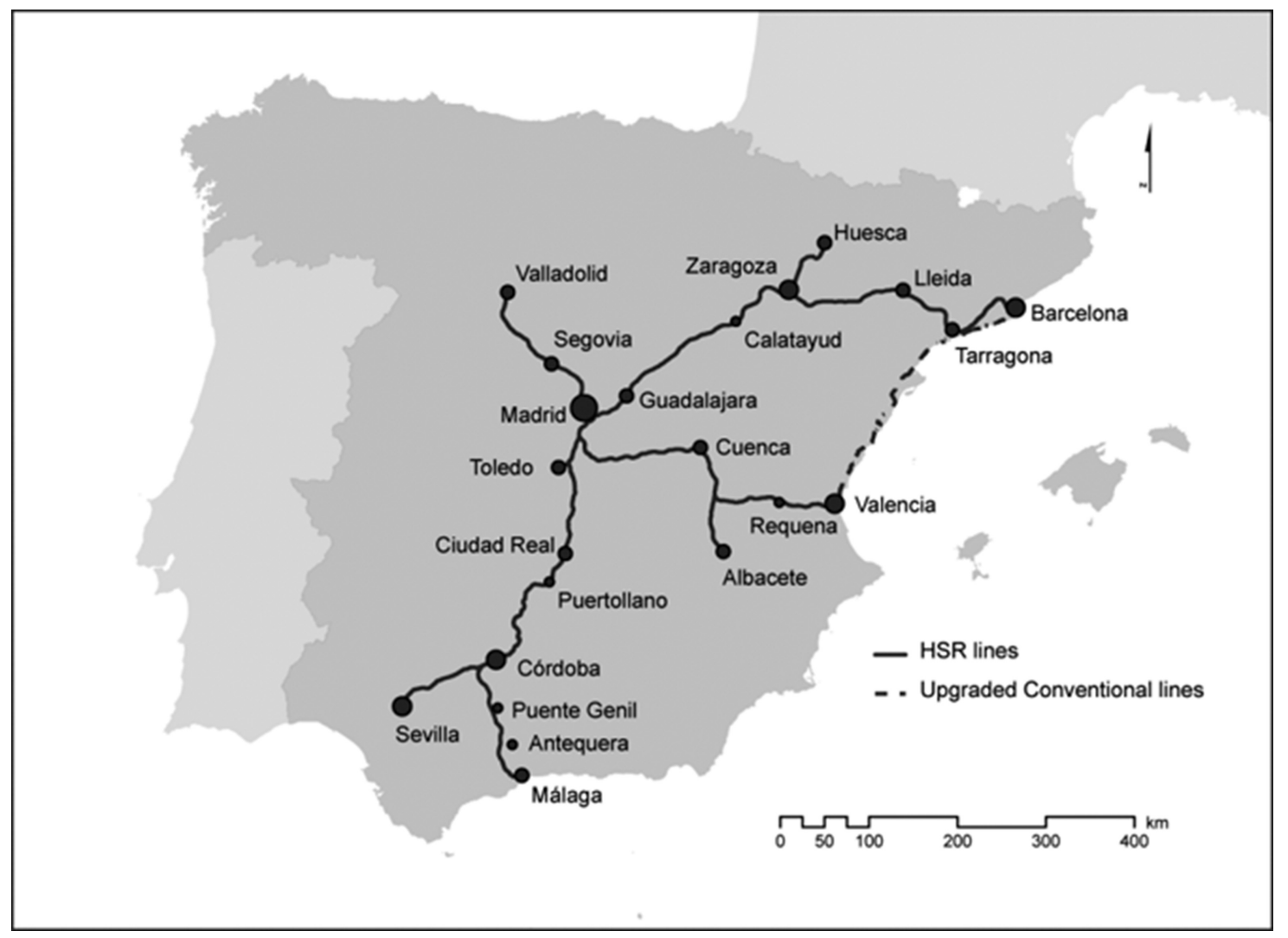

Fig. 1 HST lines in Spain in 2012

Source: Authors

$[2,3,4]$ and extended to other relationships [5]. In addition, several cities which are not on these lines can be reached by high-speed gauge adaptable trains that partially run on the new lines (ALVIA services).

During this period, the Spanish HSR expanded from a single line to a national (and soon-to-be international) network. Furthermore, unlike automobile for short distances and airplane for long distances, which both allow nearly universal connections within dense networks [6], HST is an "anchored" transport mode stopping at very few stations. Therefore, HST improves the connection between cities with stations but does not offer such benefit to other cities. In addition, in contrast to conventional rail, transferring from one train to another has almost disappeared because modern HSR run on closed lines. With conventional rail, the converging points between two lines were usually located inside stations, whereas on new HSR lines these points (grade-separated junctions) are usually located away from stations.

The HST has thus became a complex transport mode with different types of connection depending on travel time. Three primary types of HSR journeys - according to travel time and travel purpose- have been established in the literature: 1. "commuting" trips ( $<1$ hour), 2. same-day business/tourism trips ( $<2.5$ hours), and 3. occasional trips $[7,8]$. Cities with stations have experienced significant improvement in terms of accessibility and travel time. Other characteristics of supply such as fare and daily frequency must also be taken into consideration: HST connections between cities also depend on their hierarchical rank (as services are designed to accommodate as much traffic as possible). Different types of profiles within the Spanish HSR network - according to accessibility patterns and each city's own characteristics - have been described [9]: small cities less than $100 \mathrm{~km}$ from a metropolitan area (Madrid-Toledo or Madrid-Segovia) [7,10], cities up to $200 \mathrm{~km}$ away with regional HST service and discontinuous and partial integration into metropolitan areas [11], pairs of medium-sized cities linked through HSR (e.g. Ciudad Real-Puertollano), and kneecap cities located between metropolitan areas (e.g. Zaragoza, connected to Madrid and Barcelona) [7].

Most of the research on HSR has been undertaken through case studies limited to specific cities. The growing number of lines and of cities with station make it necessary to analyze entire networks in a systematic manner in order 
to understand the differences amongst cities with a high speed rail station [12]. This comparison is of paramount importance to establish the winning and the losing nodes within the HSR network [13].

Cities within a HSR network acquire a new hierarchical rank which is usually associated with immediate positive effects on the city's image, urban renewal opportunities, general optimism, etc. They also develop strategic measures to make the most of the opportunities offered by HSR. However, in many cases, reality does not match initial expectations as the predicted transformation hoped for with HSR do not materialize. As indicated in the literature [14], the existence of a HSR station does not automatically translate into useful services (with adequate fares and convenient timetables).

Previous studies - of the entire network or of some lines - only addressed the induced spatial accessibility of high-speed lines generally based on place-based indicators $[15,16]$. This paper is a contribution to a systematic analysis of the Spanish HSR network and of its utility for a specific travel purpose: touristic day-trip. It is assumed in Time Geography $[17,18,19]$ that available time at destination and associated costs are summed up in order to assess the actual tourism contribution of HSR to the different cities of the network. Such assessment of regional transport networks in Spain [20] and France [21] have generally focused on metropolitan areas commuting.

\section{Background}

\section{High-Speed Rail and Tourism}

Tourism has developed along with the expansion of transport modes. In some regions tourism currently represents a large percentage of revenue - derived from other more productive regions. The concept of "presential economy" [22,23] encompasses revenues originating from the retired population, commuters and tourists. Improvements in terms of commuting [24] and urban tourism - along with increased accessibility by HSR - might increase the relevance of the presential economy. Where automobile allow accessibility to both cities and countryside, HSR is mostly useful to travel between cities. At their destination tourists can use urban transport system to visit monuments, museums, restaurants, etc.

Urban tourism and HST affect cities and so do local strategies (including planning, management and promotion) $[10,25]$. Most case studies point to the obvious effects of HSR on tourism even though there is no systematic approach. Ex-ante studies tend to express general optimism about the HST effects on local tourism. Most of the stakeholders believe it will have positive impacts. For example, in Spain most HST stations associate a cultural surname with the city name (e.g. Málaga-María Zambrano, Segovia-Guiomar, Valencia-Joaquín Sorolla, etc.) an exception being Lleida-Pirineus which strives to attract skiers.

Different kind of trips can be defined by their duration, cost, purpose, etc. La Rocca (2008) suggested three main types of HST tourism trip: business or congress tourism (including professional events), short-duration leisure tourism (weekend), and trip tourism (one day) [26].

First, business or congress tourism occurs off the incumbents' professional activities. Their free time may be used shopping or visiting monuments and museums. Cities with important cultural resources usually promote congress venues and congress promoters are keen on organizing their events in attractive cities in order to enhance their attractiveness. HST-accessibility is an additional asset for travelers who do not bear travel costs directly. Therefore the number of events may increase thanks to HST. Many cities also improve their event infrastructures with new congress halls, hotels, etc. For example in Zaragoza, the number of events increased from 458 in 2002 to 540 in 2007 and, in parallel, the number of participants increased from 110,537 to 129,500 [27]. A similar progression has occured in the city of Le Mans in France [28].

Weekend tourism also benefits from the urban tourism and accessibility provided by the HST. Since travel costs may amount to a significant share of the total expenses driving by car or coach might be considered by individuals or groups (although parking costs - primarily in large cities - must be taken into account). However HST attractiveness (comfort and speed) increase with the distance travelled. This type of tourism can be substantially altered by HST accessibility - weekend visits become day visits - with less nights spent in the cities' hotels while the overall number of visitors increase. It happened for Cordoba [29] which has become a popular day-trip by HST from Madrid. A similar situation - unrelated to tourism - has been observed in Puertollano (an industrial city on the Madrid-Seville line) where more frequent day-trips from Madrid have largely replaced overnight professional trips, reducing the number of nights at the city's hotels [30]. This trend has also been identified in France [31].

Finally, for leisurely day-trips (shopping, tourism, or events such as sports, shows, demonstrations, etc.) travel cost and travel duration may be even more relevant. In Spain, regional HSR covering relatively short distances at high frequencies is a very convenient product for tourists. Commuters fill up the peak-hour trains, and so do tourists for off-peak trains. This pattern has been observed on trains between Toledo and Madrid, with $30 \%$ of passengers claiming to be tourists. In addition, $65 \%$ of passengers were visiting the city for the day arriving from Madrid [32]. However, the percentage of day visits had already been high 
before HST. Additionally, in the summer of 2005 (before HSR) interviews at tourist information points showed that $73 \%$ of visitors were not sleeping in Toledo [33] and that these tourists rode buses from Madrid. For Ciudad Real and Puertollano which are much smaller tourist destinations the percentage of tourists using regional HST to/from Madrid was only $11 \%$ [24].

Cities with the HST have begun to get organized in order to improve their tourism offerings. The Spanish association of HSR cities (created in 2005 and called "Red de ciudades AVE") has just launched Avexperience (a tourism product in partnership with RENFE). This offer includes train tickets between two HST cities, hotel accommodation, and city cards that offer discounts on museums, transport, restaurants, etc. for weekend visitors. Spain pass, another tourist offer aimed at foreign visitors, is an unlimited pass to all cities on the HST network [34].

The relevance of tourism packages for each city depend on various elements such as their distance from the main cities and airports and their own HST supply (fares, frequencies, travel times...). As a result, these new products may have very different impacts on the various HST cities. This research attempts to measure the utility of the HST, focusing on day-trip.

\section{Assessing the High-Speed Train Utility}

In 1992, when the HST began to run on the Madrid-Seville line all the cities on the line benefited from very significant improvements in accessibility, although the same level of service was not available for all the stations. Obviously all the services were available in Madrid whereas intermediate stops such as Córdoba were served at a lesser level (because of the availability of direct trains between Madrid and Seville and the AVE Lanzadera between Madrid, Ciudad Real and Puertollano). In any case, all of the cities were sufficiently serviced and there were no complaints. This homogeneity had existed during the initial years of the HST but has gradually disappeared with the inception of six main lines and more than 20 stations. Frequency, price per kilometre and commercial speed vary from station to station depending on the availability of regional HST (AVANT), the location of the cities within the network (intermediate stops reduce commercial speed), or city size: the larger the city the higher the frequency. However, the latter also depends on the presence of other cities on the line. For instance, 11 trains on working days and an added 11 AVE long-distance trains (with stop at Ciudad Real and Madrid as a final destination) are operating on the Ciudad Real Regional HST to Madrid (AVANT). This service is possible because the AVANT trains serve Ciudad Real (75,000 inhabitants) and Puertollano $(50,000$ inhabitants) with a total catchment area of more than 150,000 inhabitants. Without Puertollano trains would serve Ciudad Real at a lower frequency. The literature on transport economy includes this phenomenon in the concept of "transport network effects" [35].

Concerning location within the network, some cities are located on dead end lines (e.g. Toledo which is only directly connected to Madrid). Others are close to a divergence point in the network (such as Cordoba which is on the two lines between Madrid and Seville and between Madrid and Malaga). Additionally, direct trains between the southern lines (Malaga and Seville) and Barcelona bypass Madrid. Conversely, the Madrid-Valladolid line is adversely affected because it ends at the Chamartin station instead of the Atocha station which adds at least 30 minutes travel time from one to the other. In 2013, this problem will be solved by the opening of a new tunnel linking both stations (although not all the trains will be able to commute through it). In 2012, a new by-pass connecting the southern lines to the Valencia line was opened, so it is possible to travel between Malaga or Seville and Valencia without passing through Madrid-Atocha.

With this complex situation, it is necessary to assess the entire network to understand the real utility of high-speed rail for each city. This utility cannot be measured using traditional place-based accessibility indicators based on spatial or temporal proximity. HST services may be very useful for tourism visits to a city with travel time of less than one hour, but timetables or overly expensive prices may be impractical for commuting.

Time geography has introduced temporal constraints to transport connections $[17,36]$. Short travel time at a reasonable cost may not be enough for a journey to be useful if the schedules are not convenient. Furthermore, the travel details may be useful for some travel purposes (business) but not for others (day tourism). Additionally, some users may find a trip useful whereas others with different needs may not.

The metrics used in this research relate to the time available at the destination and the cost of travel in terms of both time and money. This methodology was notably used by Gutiérrez (1991) when assessing the accessibility by public transport of the villages to the north of the Madrid metropolitan area [20]. After establishing the minimum or maximum departure and arrival times, the possibility of commuting to Madrid could entail reasonable times, overly long waiting times or could be impossible. In the same manner, the possibility of spending four hours in Madrid for shopping or for administrative formalities on a labour day and the possibility of leisure travel on Sundays were assessed.

L'Hostis and Baptiste (2006) [21] assessed the quality of public transport connections in the Nord-Pas de Calais region for commuting and study purposes, considering 


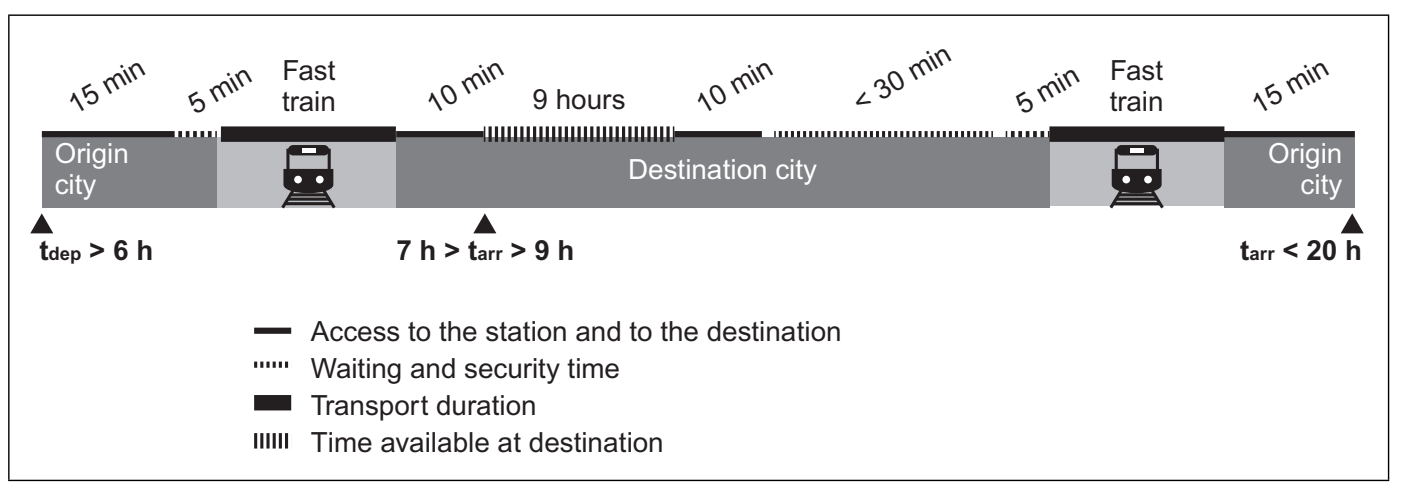

Fig. 2 Trip chain according to the principle of a "fast train at the right moment"

Source: L'Hostis and Baptiste, 2006

the complete trip chain during a single day based on the principle of the fast train at the right moment (Fig. 2). This principle holds that a link between two cities provides the requisite level of service when the user can find a fast train to go in the morning and to come back in the evening. Researchers also used this approach in the ESPON European project framework to assess the existence of useful links for business travels between European cities by HSR and airplane [37]).

Urban transit frequencies are generally high and waiting times are short as there is always a right train at the right moment. In contrast, HST frequencies are usually low so the timetables may condition the utility of the train to a high degree for some travel purposes. Even if the timetable is convenient for some trips, HST tickets being expensive the amount of time available at destination may not be worth the total expenditure.

\section{Object and methodology}

The paper aims to systematically assess the HSR utility for tourism day-trips in Spain. Shorter trips being more sensitive to service heterogeneity (fares, frequencies, timetables, etc.) one-day-trips were considered more suitable in terms of methodological approach than those on weekend.

HSR utility is primarily related to the amount of useful time available at destination and associated costs in terms of both time and money. Three primary indicators were computed with these inputs. The first is the "efficiency" of each HST connection. This indicator measures the quality of the service as a ratio between the amount of useful time at destination and the cost. Based on the efficiency value and the characteristics of each destination, two more indicators were calculated. The "reachable tourist attraction" indicator measures the capability of the inhabitants of each city to reach the tourist attractions in the other cities. The "accessible tourist market" measures how many people can easily reach one destination. To calculate these three indicators, it is necessary to establish criteria and hypothesis.

Time available at the destination was computed for every possible relation among HSR cities using the RENFE Timetables available on-line (www.renfe.es) only for trains running on high-speed lines and on the Mediterranean line between Valencia and Barcelona. Although this is not a high-speed line (but an improved line with trains connecting the $350 \mathrm{~km}$ between the two cities in 3 hours) it is obviously much more convenient for travelers both in terms of time and money than using HST lines running through Madrid (Fig. 1).

The day chosen for the calculation of the available time was Saturday because it is a day off for many employees but shopping is available and tourist attractions are open to visitors (museums, expositions, etc.). Less trains are available on the regional HST (AVANT) on Saturdays than on working days because of the smaller number of commuters.

To some extent this methodology is based on an arbitrary choice but assumptions are consistant for all of the relations considered, as the primary objective of the research is to compare between cities.

Fares or traveling times of trains running on high-speed lines vary. Regional high-speed trains (AVANT) are usually slightly slower and cheaper than long-distance high-speed trains. Transferring at intermediate stations may be more convenient than traveling on direct trains. Because the paper analyses utility for tourism trips, it is assumed that users favor cheaper trains, as these passengers are flexible in terms of departure and arrival times. However, since tourists visit for only one day, it was assumed that they would try to maximize their time at destination, even if they would not need to arrive exceedingly early.

A time-value ratio was used to systematize choice between one or another train option, considering differences in ticket costs and arrival times. This ratio was necessary to compare the differences in traveling times, the amount of useful time spent at destinations and ticket costs. The ratio 


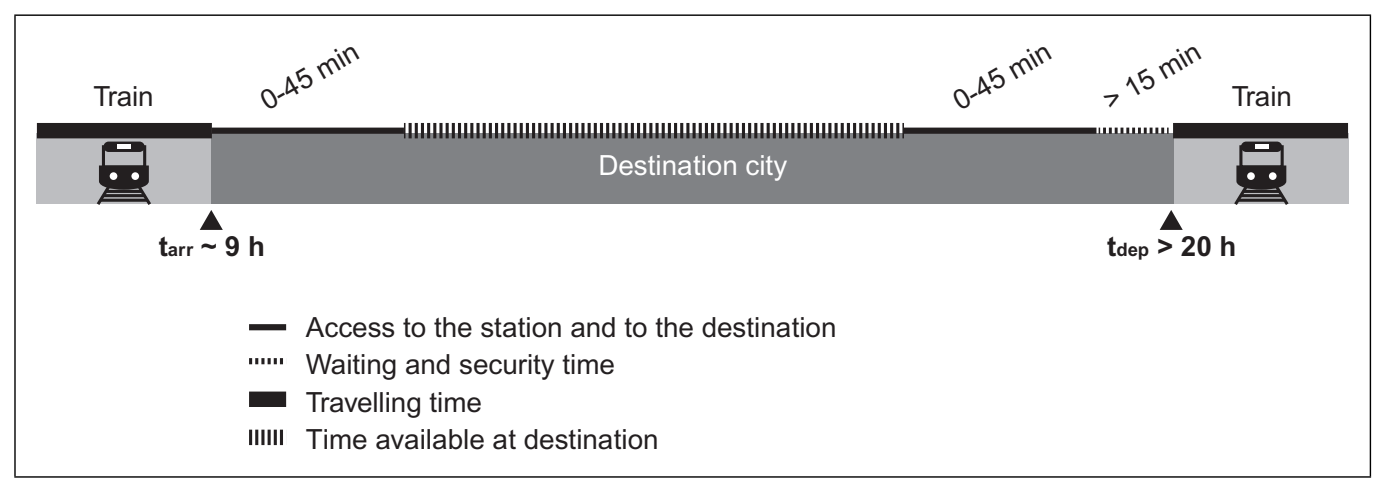

Fig. 3 Tourism day-trip chain considered to calculate the time available at destination Source: Adapted from L'Hostis and Baptiste, 2006

used for the calculations of time available at the destination was $20 € / \mathrm{h}(0.33 € /$ minute $){ }^{1}$

This hypothesis favored the last low-priced outbound train arriving before $9 \mathrm{am}$. If the low-priced train arrived after $9 \mathrm{am}$, the time gain was compared with the cost increase. For the return train, the first low-priced train departing after 8 pm was favored.

The amount of useful time spent at the destination is less than the difference between the arrival time and the departure time of the return train. The amount of useful time must be reduced because of the time spent for security checks at the train station prior to trains departure and the time needed to arrive from the HST station to the city centre and vice versa. The security time for all the stations was considered to be fifteen minutes. The arrival time was zero when the stations were located within the city centre (as we considered tourists begin their experience in the stations). When the station was located outside the city, the connecting or access time between the station and the city centre (and vice versa) by public transport (urban buses) was added. In some cases, this amount of time penalises service to a remarkable degree.

When transfer between trains at the same station was necessary, a difference of at least 10 minutes between arrival time and departure time was added. If the change was made between the Chamartín and Atocha stations in Madrid, at least 45 minutes were added. Fig. 3 shows the adaptation of L'Hostis and Baptiste's methodology.

With all of these elements taken into consideration, three main sets of data were calculated for every city to city relations: the total time available at the destination $\left(t_{\text {dest }}\right)$, the time spent travelling $\left(t_{\text {travel }}\right)$ and the travel cost (tourist class fares without discount) in terms of money ( $\left.€_{\text {travel }}\right)$. With these elements, the "efficiency" (E) of the money (or time)

\footnotetext{
${ }^{1}$ A survey of HSR passengers in 2007 established the figure $14 \mathrm{C} / \mathrm{h}$ for non-mandatory travel purposes and $3.92 \mathrm{C} / \mathrm{h}$ for headway time [38]. These values were updated and rounded to $20 € / \mathrm{h}$.
}

invested to obtain useful time available at the destination were calculated.

$$
\mathrm{E}_{€}=\mathrm{t}_{\text {dest }} / \boldsymbol{C}_{\text {travel }} \text { or } \mathrm{E}_{\mathrm{t}}=\mathrm{t}_{\text {dest }} / \mathrm{t}_{\text {travel }}
$$

This indicator shows how useful HST services are for all of the combinations of day-trips. They are an assessment of the economic viability of a one-day-trip by HST as a comparison between the amount of money spent on train tickets and the hotel costs for a weekend trip.

A good transportation service is not a reason of its own to visit a city; there should also be something worth visiting. This is why the cultural tourism relevance of each city was assessed according the number of monuments (real estate) designated as BICs (Bien de Interés Cultural- "Heritage of Cultural Interest"). A BIC is any piece of real estate or personal property with any type of artistic, historic, palaeontological, scientific or technical interest declared as such by the relevant administration. Any location with documentary and bibliographic heritage and green areas or parks endowed with artistic, historic or anthropologic interest can also be designated BICs.

However, the value of a BIC as a tourist attractor is not the same for all of these locations. Some BICs have higher tourist interest than others (e.g. the Roman aqueduct in Segovia) and some cities' overall historic interest is higher than the sum of their monuments. For this reason, when a city has been nominated to the World Heritage by the Unesco its BICs was multiplied by two, whereas if the city's historical sites were merely listed by the Spanish Ministry of Culture the value of each BIC was only multiplied by 1.25 .

The number of BICs indicates the relevance of a city as a cultural destination for tourism, although this number does not include seaside tourism or features such as fairs, events and commercial offers. Unfortunately, better data (such as the number of tourist visits) were not available.

All these data were input for the calculation of two indicators to measure the utility of the HSR offer for tourism 
day-trips. The first is the "reachable tourist attraction" (RTA), which measures the ease of visiting all of the other cities' BICs from each city traveling with the HST. It is the addition of the product of the efficiency of the money invested in the trip with the number of BICs at the destination:

$$
\mathrm{RTA}_{\mathrm{ij}}=\sum \frac{\mathrm{t}_{\text {dest } \mathrm{j}}}{\epsilon_{\text {travel } \mathrm{ij}}} \cdot \mathrm{BICs}_{\mathrm{j}}
$$

Although this indicator has produced interesting results, it is not elaborated in the results section, as its policy implications are limited. This indicator only illustrates that the citizens of some HST cities have access to more destinations in better conditions. It is more useful to work on the second indicator, the "accessible tourist market" (ATM) using the HST for each city, which measures the number of visitors that can be attracted. This figure is obtained by adding the products of the population of all of the tourists' origins to the efficiency of the money invested in the trip. Population data obtained from the National Statistics Institute for 2011 were used.

$$
\mathrm{ATM}_{\mathrm{ij}}=\sum \frac{\mathrm{t}_{\text {dest } \mathrm{j}}}{\mathrm{\epsilon}_{\text {travel } \mathrm{ij}}} \cdot \mathrm{P}_{\mathrm{i}}
$$

The policy implications of this indicator are more relevant as it gives an example of the utility of marketing campaigns to promote touristic resources of the cities.

Finally, in order to compare the utility of the service in each city, population-weighted averages were computed for the time available at destination and its associated costs for each destination city.

$$
\mathrm{T}_{\mathrm{R} i j}=\frac{\sum\left(\mathrm{t}_{\text {dest ij } \mathrm{P}_{\mathrm{i}}}\right)}{\sum \mathrm{Pi}} \text { and } \mathrm{C}_{\mathrm{R}} \mathrm{ij}=\frac{\sum\left(€_{\text {travel ij }} \cdot \mathrm{P}_{\mathrm{i}}\right)}{\sum_{\mathrm{Pi}}}
$$

\section{Results}

Spanish high-speed trains run on six lines which all end in Madrid. Thus, Madrid is the only city offering direct trains to all the other cities. Southern and northeastern (Barcelona) lines are connected and bypass Madrid, and since June 2012 a by-pass between South and East (Valencia) has been in service. The number of direct trains between each origin (rows) and destination (columns) for a Saturday in May 2012 are shown in Table 1.

This table indicates the heterogeneity of the level of service in the different cities. Although 205 connections by high-speed train can be made every day from Madrid, Huesca is the origin of only four connections provided by a single train to Madrid. It is therefore necessary to systematically assess the utility of all these trains and connections.

\section{The HST's Utility for daily tourism}

Considering the hypothesis described in the methodology, the time available at the destination for a day visit by high-speed rail was measured for every origin and destination between the 22 cities evaluated using the RENFE Timetables for a Saturday in May. Fig. 4 provides an example of the day-trip route between Toledo and Zaragoza with a connection in Madrid-Atocha for which both AVANT and AVE trains are used.

Additionally, travel times and costs for tourist class travel were collected. This data collection resulted in $462(22 \times$ 21) possible connections between cities. Obviously, many of these possible connections are not convenient for a day-trip because of one or both of the following factors: too little time available at the destination or ticket too expensive.

The matrix in Table 2 indicates the useful time available at each destination for each pair. When the time available at the destination is more than 8 hours, the numbers are provided in green (142 cases). Yellow is used when the time available at the destination is between 6 and 8 hours ( 80 pairs), and red is used when the time available is under 6 hours $(240$ pairs). As observed, Madrid enjoys a longer time available as both an origin and a destination.

Travel costs are taken into account to compute the Efficiency (time available at destination obtained per euro) of the money invested in day-trips between all the origins (Table 3). When efficiency is under $3 \mathrm{~min} / \mathrm{C}$ (a cost of $20 €$ per hour at the destination), the day-trip by HST was deemed not to be economically viable (numbers in red). When an entire day (11 hours at the destination, from 9 a.m. to 8 p.m.) would cost $220 €$., a weekend trip would be better than a day-trip as hotel costs less than train.

When the efficiency is above $11 \mathrm{~min} / €$ (a cost of $5.45 €$ per hour at destination), day-trips are deemed extremely convenient (numbers in green), as the amount of money invested in train tickets is less than that invested in sleeping at the destination (considering a cost of $60 €$ for a hotel and meals to gain 11 useful hours on the additional day). Yellow has been used for efficiency between 3 and $11 \mathrm{~min} / \mathrm{C}$. Only 58 of 462 possible connections are economically viable for day-trips considering the hypothesis (green), whereas travellers could consider sleeping at their destinations and extending their trip for 133 connections (yellow).

For many connections with long periods of time spent at the destination as the best option (in green in Table 2, e.g., Madrid-Barcelona, 11.5 hours) the ticket cost was 


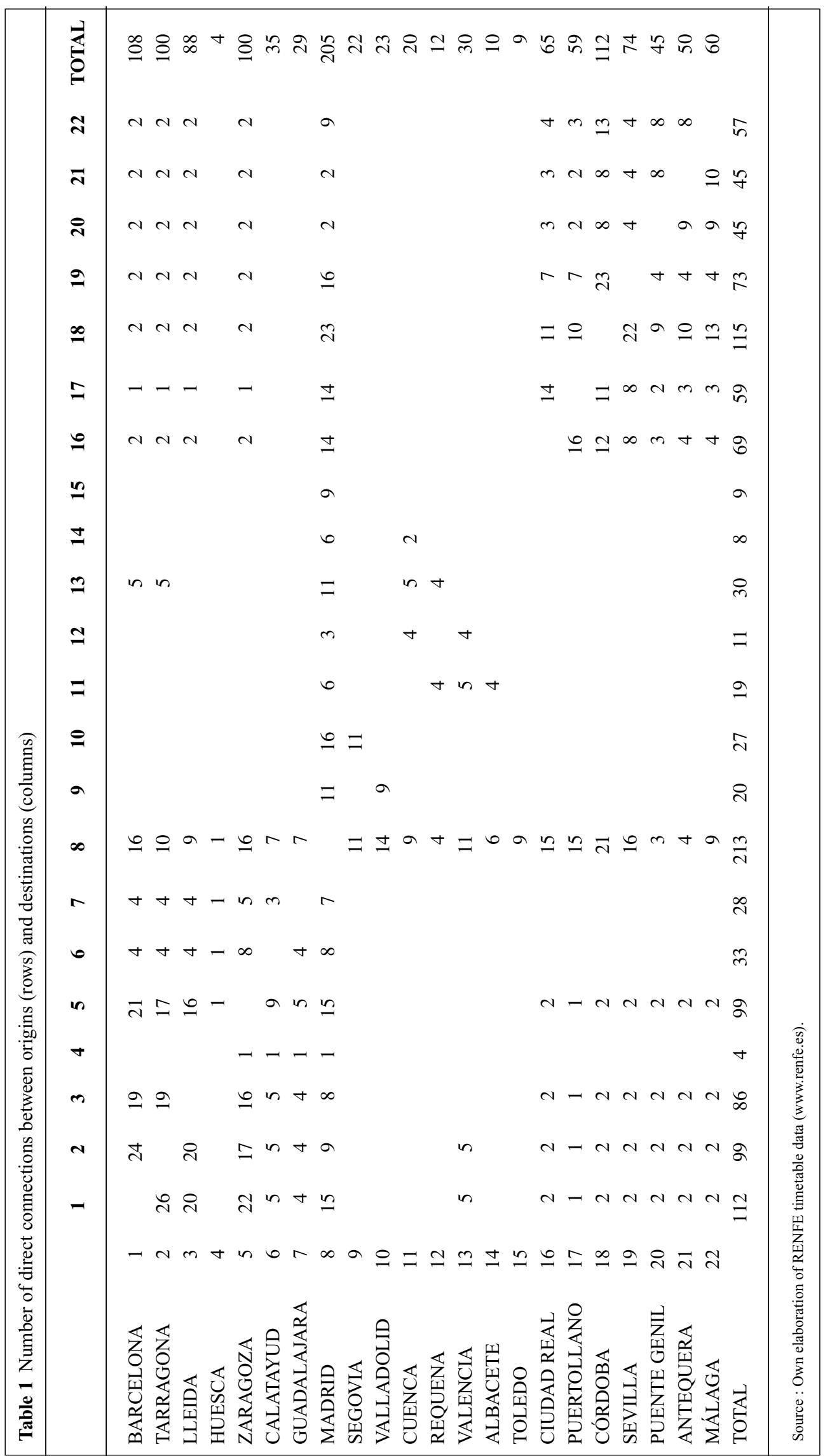

Necplus 


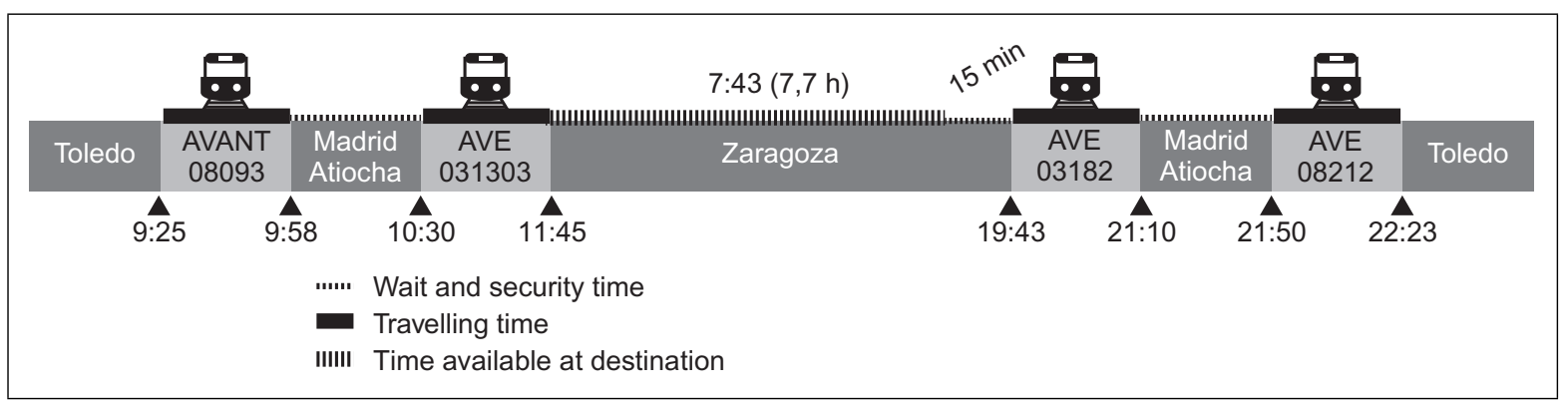

Fig. 4 Tourism day-trip route considered between Toledo and Zaragoza

Source: Adapted from L'Hostis and Baptiste, 2006

reducing efficiency (turning into yellow in Table 3). This result may be different for other trip purposes (i.e., business) or durations (i.e., weekend trips).

Table 3 also indicates substantial differences between cities. Although Madrilenians can make day-trips to nearly all the cities (green and yellow), people from Huesca can only visit 7 destinations. In addition, Madrid can be visited on a day-trip from all the cities (Puente Genil and Antequera being within the limit), whereas Huesca cannot be visited on a day-trip by HST from any city. The situation is similar for Requena, as it can only be visited from the cities on its own line (i.e., Valencia, Cuenca and Madrid). Madrid obviously benefited from the radiocentric shape of the HSR network, as well as from the higher frequencies and number of trains.
These differences were also illustrated in a graph with the available times and costs for connections from Madrid and Barcelona (Fig. 5). Most day-trips from Madrid are efficient, whereas for Barcelona only the cities on the line to Madrid are reachable and are associated with sufficient available time and low enough costs. The slope of the line linking each point to the origin of the graph illustrates efficiency.

These graphs are also useful for comparisons of other cities with similar patterns [39]. Such a comparison can be made among cities less than one hour from Madrid (Toledo, Segovia and Guadalajara) which are compared in fig. 6. In Toledo, only direct trains to Madrid are available, whereas in Segovia trains to Madrid and Valladolid are available. These two cities offer regional HST service (AVANT), whereas

Table 2 Useful hours available at destination (columns) for all the possible links using HSR

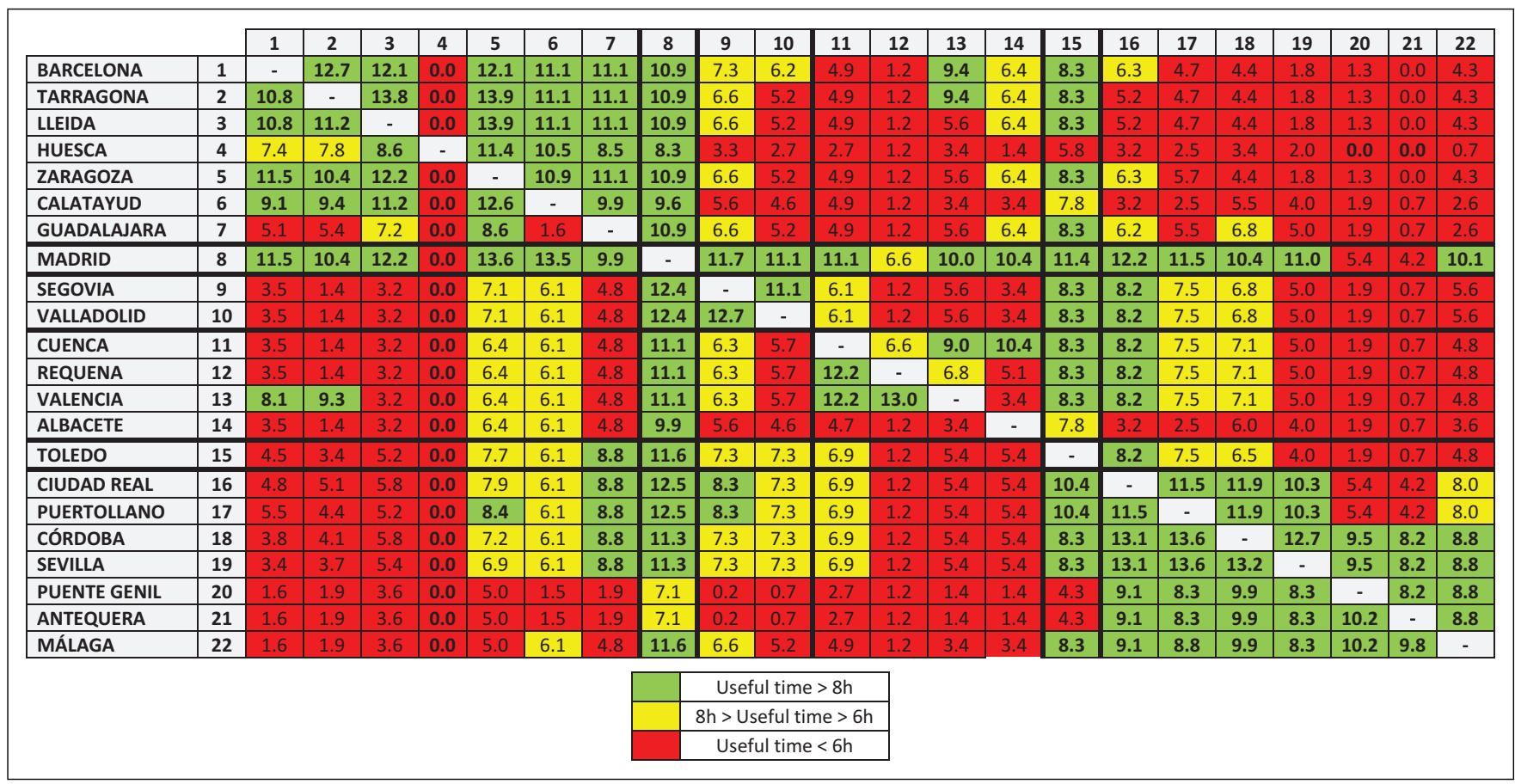

Source: Author's elaboration of RENFE Timetables for a Saturday day-trip in May 2012 
Table 3 Efficiency (useful minutes at destination per euro) of all the possible links using HSR

\begin{tabular}{|c|c|c|c|c|c|c|c|c|c|c|c|c|c|c|c|c|c|c|c|c|c|c|c|}
\hline & & 1 & 2 & 3 & 4 & 5 & 6 & 7 & 8 & 9 & 10 & 11 & 12 & 13 & 14 & 15 & 16 & 17 & 18 & 19 & 20 & 21 & 22 \\
\hline BARCELONA & 1 & - & 26.1 & 14.2 & 0.0 & 7.7 & 5.4 & 4.5 & 3.5 & 2.0 & 1.5 & 1.2 & 0.2 & 7.9 & 1.4 & 2.4 & 1.7 & 1.3 & 1.2 & 0.5 & 0.3 & 0.0 & 0.9 \\
\hline TARRAGONA & 2 & 25.4 & - & 29.7 & 0.0 & 11.9 & 7.0 & 5.1 & 4.6 & 2.5 & 1.5 & 1.5 & 0.3 & 9.4 & 1.7 & 3.1 & 1.9 & 1.6 & 1.4 & 0.5 & 0.4 & 0.0 & 1.1 \\
\hline LLEIDA & 3 & 15.0 & 32.6 & - & 0.0 & 17.4 & 9.4 & 5.8 & 5.1 & 2.7 & 1.7 & 1.6 & 0.3 & 1.3 & 1.9 & 3.4 & 2.0 & 1.7 & 1.5 & 0.6 & 0.4 & 0.0 & 1.1 \\
\hline HUESCA & 4 & 3.4 & 4.9 & 6.9 & - & 27.1 & 14.0 & 6.0 & 4.9 & 1.6 & 1.1 & 1.0 & 0.4 & 0.9 & 0.5 & 2.9 & 1.4 & 1.0 & 1.0 & 0.5 & 0.0 & 0.0 & 0.2 \\
\hline ZARAGOZA & 5 & 6.6 & 8.9 & 15.2 & 0.0 & - & 25.0 & 8.8 & 6.8 & 3.4 & 2.0 & 1.9 & 0.4 & 1.5 & 2.2 & 4.3 & 2.8 & 2.4 & 1.6 & 0.6 & 0.4 & 0.0 & 1.2 \\
\hline CALATAYUD & 6 & 4.5 & 6.0 & 9.5 & 0.0 & 24.9 & - & 11.1 & 8.2 & 3.8 & 2.2 & 2.3 & 0.4 & 1.0 & 1.4 & 5.2 & 1.7 & 1.3 & 1.8 & 1.2 & 0.6 & 0.2 & 0.8 \\
\hline GUADALAJARA & 7 & 2.1 & 2.5 & 3.7 & 0.0 & 6.8 & 1.9 & - & 21.5 & 8.0 & 3.5 & 3.4 & 0.6 & 2.1 & 3.5 & 10.1 & 5.2 & 4.2 & 2.9 & 1.8 & 0.8 & 0.2 & 0.9 \\
\hline MADRID & 8 & 3.7 & 4.4 & 5.6 & 0.0 & 8.5 & 11.5 & 19.6 & - & 24.7 & 13.3 & 12.5 & 3.7 & 4.7 & 7.9 & 35.8 & 17.9 & 14.1 & 7.3 & 5.0 & 2.6 & 1.9 & 4.3 \\
\hline SEGOVIA & 9 & 1.0 & 0.5 & 1.3 & 0.0 & 3.7 & 4.3 & 6.2 & 40.8 & - & 18.1 & 4.8 & 0.5 & 2.3 & 2.1 & 13.3 & 8.3 & 6.7 & 3.2 & 2.0 & 0.8 & 0.3 & 2.1 \\
\hline VALLADOLID & 10 & 0.9 & 0.5 & 1.1 & 0.0 & 3.1 & 3.4 & 3.7 & 18.2 & 27.1 & - & 3.7 & 0.5 & 2.0 & 1.7 & 8.3 & 6.0 & 5.0 & 2.7 & 1.7 & 0.8 & 0.2 & 1.9 \\
\hline CUENCA & 11 & 0.8 & 0.4 & 1.0 & 0.0 & 2.4 & 2.9 & 3.2 & 10.8 & 4.2 & 2.8 & - & 7.4 & 8.8 & 24.5 & 6.2 & 4.8 & 4.1 & 2.7 & 1.5 & 0.6 & 0.2 & 1.4 \\
\hline REQUENA & 12 & 0.7 & 0.3 & 0.8 & 0.0 & 1.9 & 2.1 & 2.2 & 6.3 & 2.8 & 2.1 & 13.8 & - & 10.3 & 1.7 & 4.0 & 3.4 & 2.9 & 2.1 & 1.3 & 0.5 & 0.2 & 1.2 \\
\hline VALENCIA & 13 & 6.9 & 9.3 & 0.7 & 0.0 & 1.7 & 1.9 & 1.9 & 5.2 & 2.4 & 1.8 & 11.0 & 19.9 & - & 1.0 & 3.4 & 2.9 & 2.6 & 1.9 & 1.1 & 0.5 & 0.2 & 1.1 \\
\hline ALBACETE & 14 & 0.8 & 0.4 & 0.9 & 0.0 & 2.2 & 2.5 & 2.8 & 7.5 & 3.5 & 2.1 & 10.2 & 0.4 & 1.0 & - & 4.8 & 1.6 & 1.2 & 1.9 & 1.1 & 0.6 & 0.2 & 1.0 \\
\hline TOLEDO & 15 & 1.3 & 1.3 & 2.1 & 0.0 & 4.0 & 4.3 & 11.3 & 36.6 & 11.6 & 6.3 & 5.4 & 0.6 & 2.2 & 3.3 & - & 8.2 & 6.6 & 3.3 & 1.6 & 0.8 & 0.3 & 1.8 \\
\hline CIUDAD REAL & 16 & 1.3 & 1.7 & 2.1 & 0.0 & 3.5 & 3.1 & 6.5 & 18.4 & 8.4 & 4.8 & 4.2 & 0.5 & 1.8 & 2.5 & 10.4 & - & 68.7 & 11.3 & 5.5 & 3.6 & 2.6 & 4.4 \\
\hline PUERTOLLANO & 17 & 1.4 & 1.4 & 1.7 & 0.0 & 3.5 & 2.8 & 5.7 & 15.2 & 7.3 & 4.4 & 3.9 & 0.5 & 1.7 & 2.3 & 9.1 & 68.2 & - & 13.8 & 6.0 & 4.0 & 2.8 & 4.7 \\
\hline CÓRDOBA & 18 & 0.9 & 1.1 & 1.7 & 0.0 & 2.3 & 2.1 & 3.8 & 6.2 & 3.4 & 2.7 & 2.5 & 0.3 & 1.4 & 1.8 & 3.9 & 11.5 & 15.3 & - & 24.9 & 29.3 & 17.2 & 13.0 \\
\hline SEVILLA & 19 & 0.7 & 0.9 & 1.4 & 0.0 & 2.0 & 1.8 & 3.3 & 5.1 & 2.9 & 2.4 & 2.2 & 0.3 & 1.2 & 1.5 & 3.3 & 7.8 & 8.8 & 18.9 & - & 11.9 & 8.7 & 7.5 \\
\hline PUENTE GENIL & 20 & 0.4 & 0.6 & 1.1 & 0.0 & 1.7 & 0.4 & 0.7 & 3.0 & 0.1 & 0.2 & 0.8 & 0.3 & 0.3 & 0.4 & 1.6 & 6.1 & 6.5 & 28.8 & 10.3 & - & 48.6 & 22.2 \\
\hline ANTEQUERA & 21 & 0.4 & 0.6 & 1.1 & 0.0 & 1.7 & 0.4 & 0.6 & 2.8 & 0.1 & 0.2 & 0.8 & 0.3 & 0.3 & 0.4 & 1.5 & 5.6 & 5.8 & 20.9 & 8.8 & 60.4 & - & 34.9 \\
\hline MÁLAGA & 22 & 0.4 & 0.6 & 1.1 & 0.0 & 1.6 & 1.8 & 1.7 & 5.0 & 2.5 & 1.6 & 1.5 & 0.3 & 0.8 & 0.9 & 3.1 & 5.0 & 5.2 & 14.8 & 7.1 & 25.7 & 39.0 & - \\
\hline & & & & & & & & & \multicolumn{6}{|c|}{ Efficiency $>11 \mathrm{~min} / €(<5.45 € / \mathrm{h})$} & & & & & & & & & \\
\hline & & & & & & & & & \multicolumn{6}{|c|}{$11 \mathrm{~min} / €>$ Efficiency $>3 \mathrm{~min} / €$} & & & & & & & & & \\
\hline & & & & & & & & & \multicolumn{6}{|c|}{ Efficiency $<3 \mathrm{~min} / €(>20 € / \mathrm{h})$} & & & & & & & & & \\
\hline
\end{tabular}

Source: Author's elaboration of RENFE Timetables for a Saturday day-trip in May 2012.

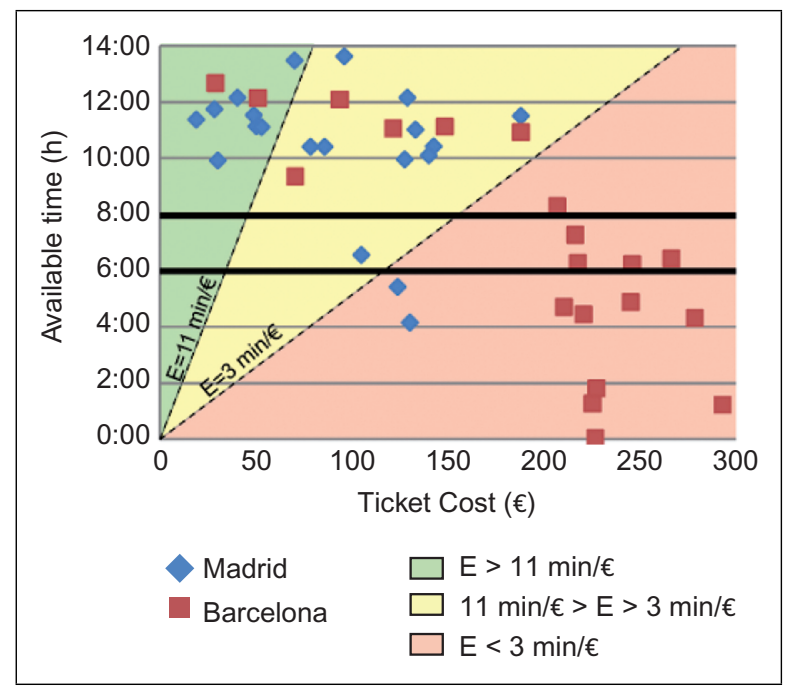

Fig. 5 Available time vs. ticket costs for all connections from Barcelona and Madrid

Source: Author's elaboration of RENFE Timetables for a Saturday day-trip in May 2012

Guadalajara does not, but the latter benefits from a better connection to the cities on the Barcelona line.

When intermediate medium cities between metropolitan areas such as Zaragoza and Cordoba are analysed, the

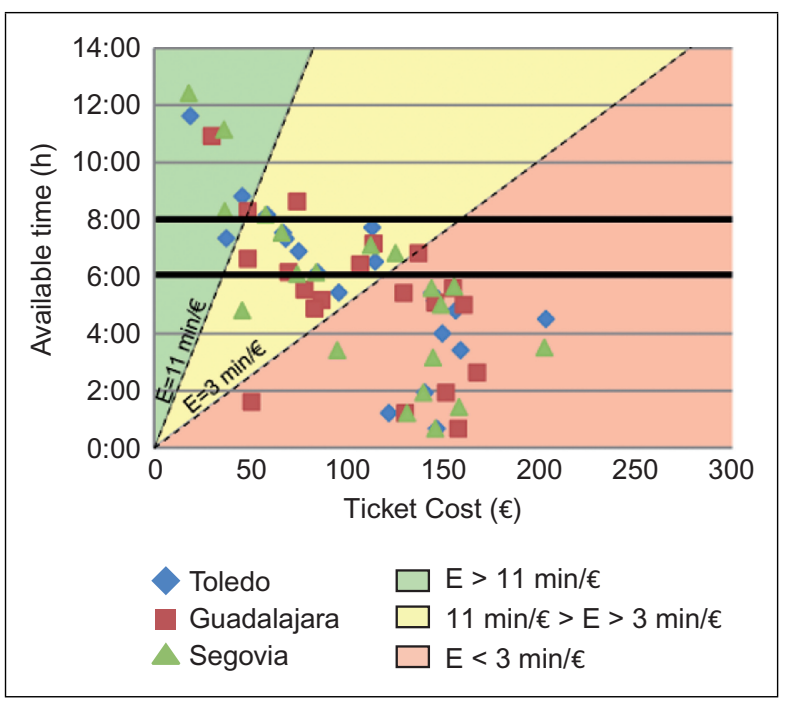

Fig. 6 Available time vs. ticket costs for all connections from Toledo, Guadalajara and Segovia

Source: Author's elaboration of RENFE Timetables for a Saturday day-trip in May 2012

superior connectivity of Cordoba located at the divergence point of the lines to Malaga and Seville (Fig. 1) results in generally more available times and lower costs (Fig. 7). 


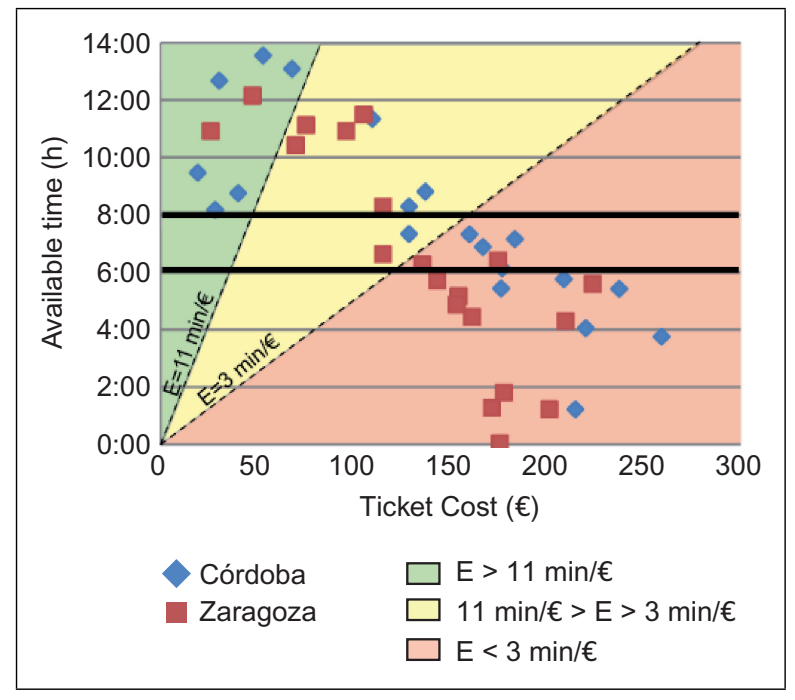

Fig. 7 Available time vs. ticket costs for all connections from Zaragoza and Córdoba

Source: Author's elaboration of RENFE Timetables for a Saturday day-trip in May 2012

\section{Accessible tourist market for day-trips}

As described in the methodology, the efficiency of the connections provided by HST does not indicate how many people may access each city. Access to an efficient connection in a large city such as Madrid is more relevant than connection to a small town. As a result, not all the tourists' origins have the same interest. The larger the city population the more significant the connection is.

Fig. 8 indicates the tourist market accessible by HST for each city (total tourist hours available in millions per Euro) which is calculated by adding the products of the efficiency of each origin to its population. Cities close to Madrid (such as Toledo, Segovia or Guadalajara) have a larger tourist market and an efficient connection. Although farther from Madrid, intermediate cities may attract tourists from cities on both sides of the line as is the case for Ciudad Real, Puertollano, Tarragona and Calatayud. Conversely, cities at the ends of lines (such as Malaga, Seville or Barcelona) have smaller tourist markets accessible by HST for day-visits. Such a tourist market is present in Requena because of

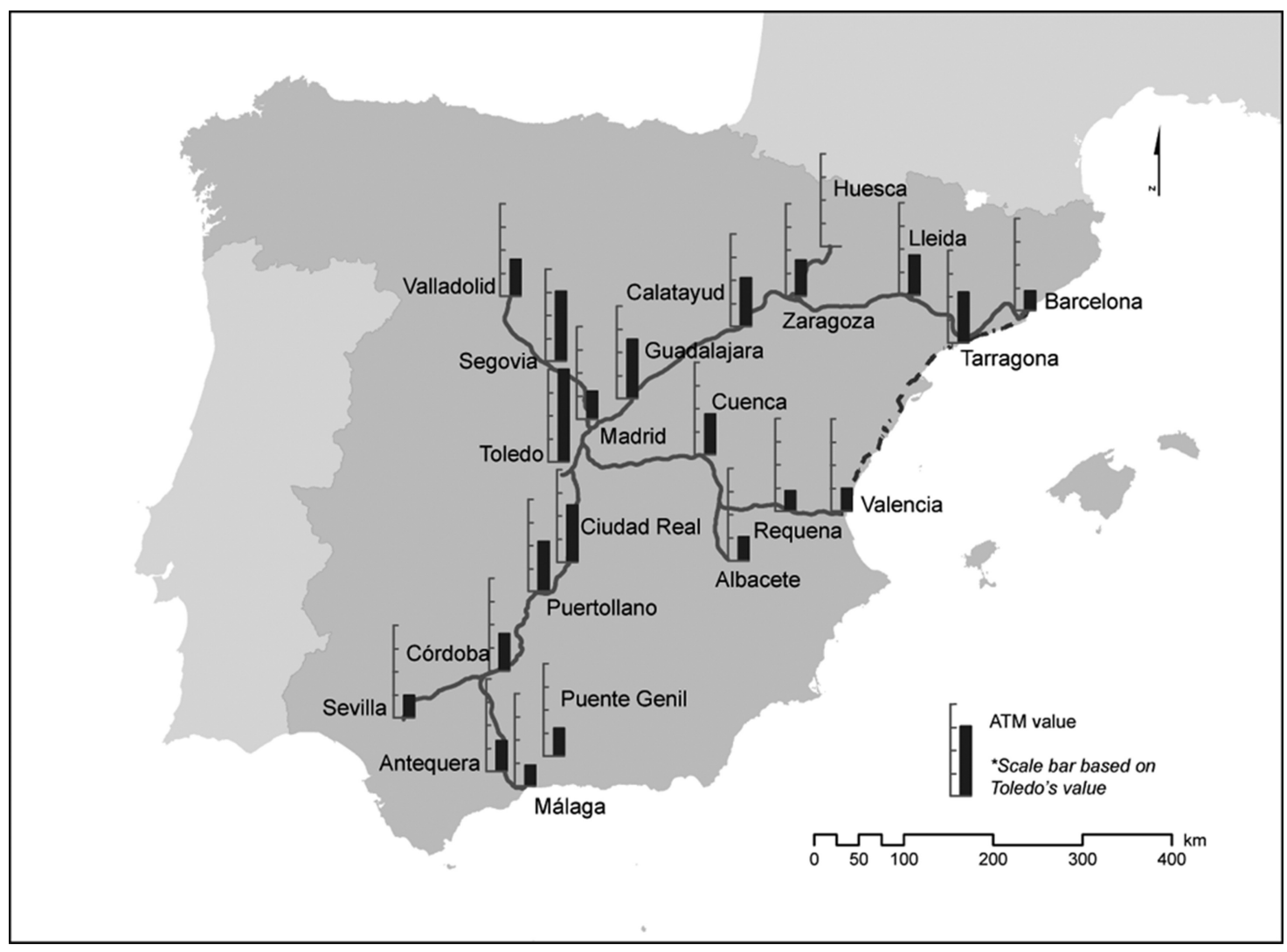

Fig. 8 Accessible tourist market (ATM) using the HST for each city

Source: Author's elaboration of RENFE Timetables for a Saturday day-trip in May 2012 and INE population data 


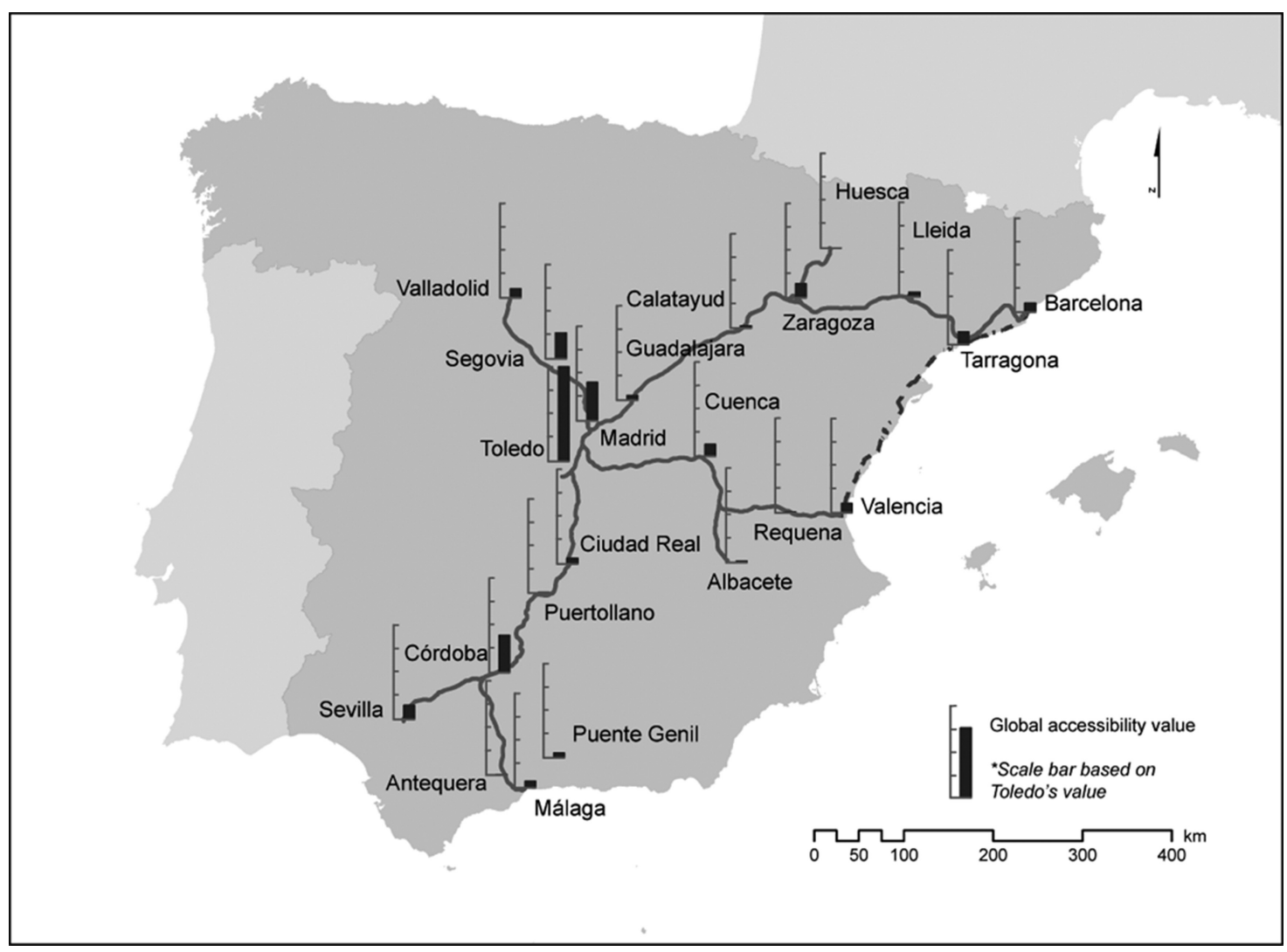

Fig. 9 Global day-trip accessibility by HST considering the tourism relevance of each destination Source: Author's elaboration of RENFE Timetables for a Saturday day-trip in May 2012 and INE population data

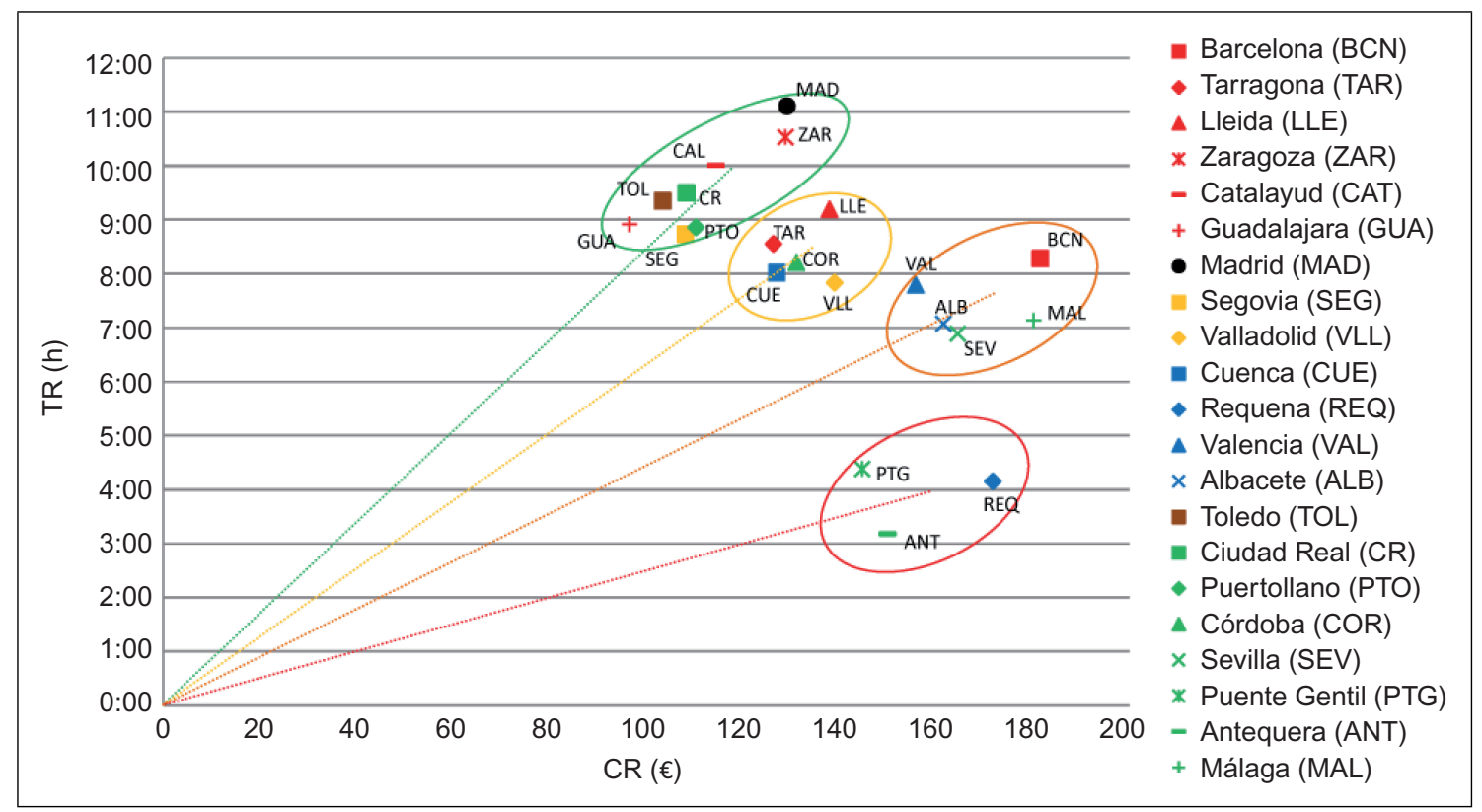

Fig. 10 Weighted average of time available at destination vs. costs. The slopes of the dotted lines represent the efficiency of time available at destination with each euro spent in tickets

Source: Author's elaboration of RENFE Timetables for a Saturday day-trip in May 2012 


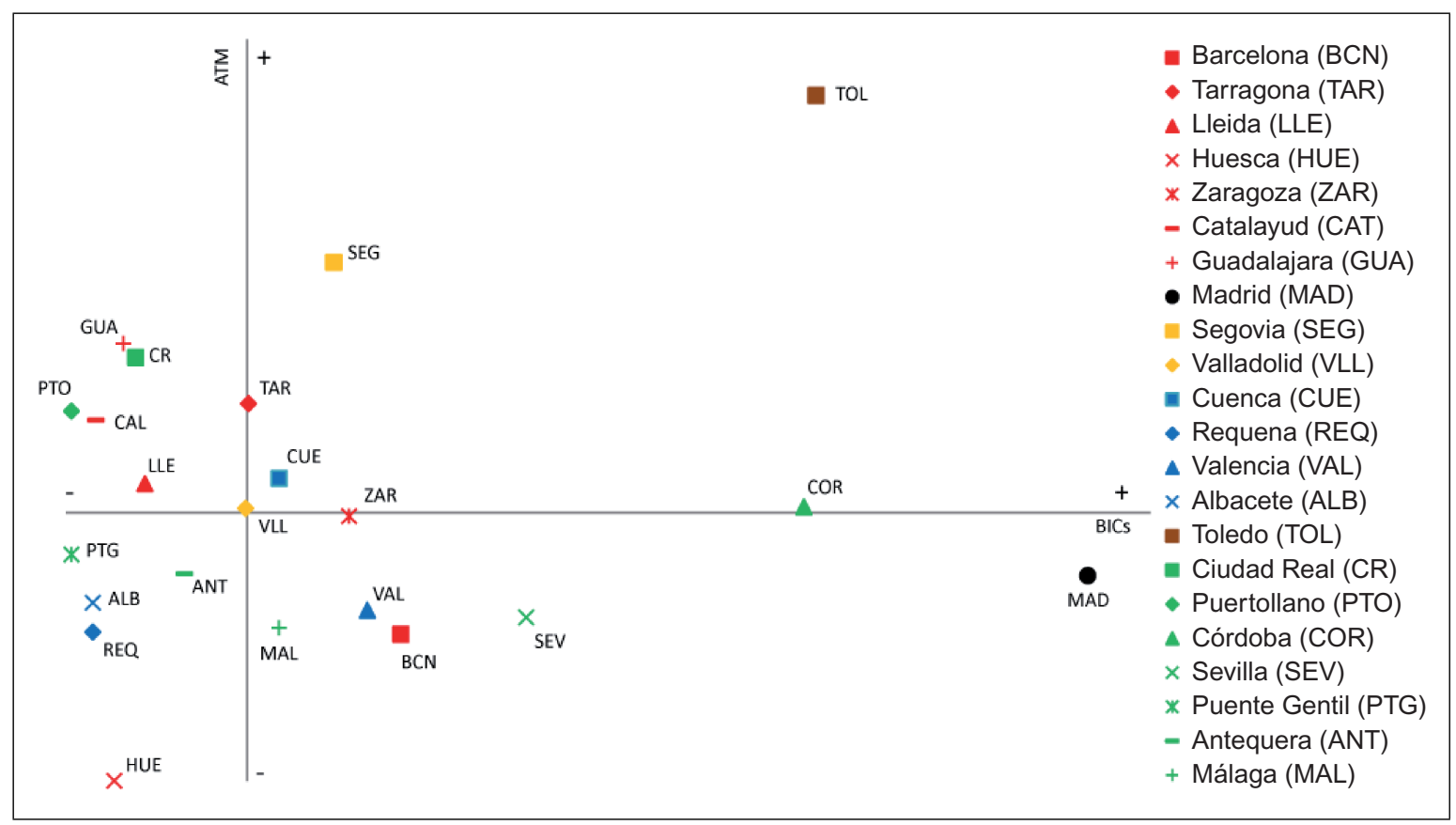

Fig. 11 Cities' relative position in terms of ATM and BICs. The origin of the figure $(0,0)$ is the median of both values

the limited frequency of service. This relationship proves that a station is not sufficient to experience an HST effect.

Additionally, cities in the South (such as Cordoba) take advantage of the higher number of close connections as several stations are located in the neighborhood. Conversely, Barcelona does not take much advantage of its HST connection to attract daily tourists.

However, the real utility of the HSR accessibility of each city can not solely be assessed by the ATM; the city's relevance as a tourist destination must also be considered. Multiplying the results of the tourist market accessible for day-trips by the number of BICs, used as indicator of the relevance of the cultural tourism supply, the importance of the total day-trip accessibility by HST for day tourism for each city may be measured, at least in relative terms. As observed in fig. 9, The number of day-trips by HST in Toledo should be higher. Expectations for this type of tourism in Albacete, Puertollano, Puente Genil, Requena or Huesca are moderate.

In order to broaden the measure and comparison of the the utility of HST for day-trips, two weighted averages have been calculated for each city, considering the size of the cities from which the tourists may originate. The weighted average of the time available at the destination is indicated in the graph in fig. 10 in comparison with the weighted average of costs. This weighted average entails the calculation of the gravity centre of the points provided in figures 5-7 for each city. As observed, there are significant differences in the utility of the HST services in attracting day-trip visitors and the ticket costs associated. Four groups of cities emerged of a cluster analysis. The first group includes the cities in which more time is available and costs are lower, or the cities with high accessibility by HST for one-day visits. These cities are Madrid, Zaragoza, Calatayud, Ciudad Real, Toledo, Guadalajara, Segovia and Puertollano. All of these cities have similar average efficiencies (slopes on the graph). The second group includes Tarragona, Lleida, Cuenca, Córdoba and Valladolid. These cities are still attractive for day-trips, although the associated costs are slightly too high. This situation deteriorates in the third group, which includes Valencia, Barcelona, Albacete, Seville and Malaga. Their attractiveness as day-trip destinations is limited, primarily because they are at the end of their HSR lines so average useful times at destination are reduced whereas travel costs reach the highest values. Finally, the last group with Puente Genil, Antequera, Requena and Huesca, are all small cities with low frequencies and/or remote stations, which should not have overly high expectations for daily tourism visits from the rest of the high-speed rail cities.

\section{Conclusions}

The development of HSR lines in the last 30 years has evolved from single lines connecting metropolitan areas to rather complex networks extending even beyond national limits and connecting cities with different patterns. Until now, most of the HSR literature consisted of case studies of specific lines. However, today global assessment and 
analysis of the entire network are necessary to identify the winners and the losers in this process.

In the Spanish case, all the lines converge in Madrid, which thus becomes very accessible from the other cities for tourism day-trips. In contrast, because of low frequencies, intermediate small cities do not offer very useful connections by HST. Similarly, cities at the ends of lines are not adequately connected to cities that are not on their own lines.

Based on the results of this paper, four main situations regarding the potential for urban tourism development using the HST can be identified (Fig. 11) by a comparison of the tourist Supply (BICs) and the Accessible Tourist Market (ATM):

1. Cities with a large ATM (usually close to Madrid) and a robust tourist supply. HSR accessibility improvement provides very convenient connection between these cities and Madrid. Many foreign visitors decide to stay overnight in Madrid, making one-day trips to these surrounding cities, including Toledo and Segovia. Their strategies should be oriented towards extending the length of the visit and, thus, turning day-trips into weekend trips.

2. Cities with a large ATM but a poor tourist supply (BICs). These cities (which include Puertollano and Ciudad Real) should develop cultural or leisure activities (events, congresses, concerts, etc.) to attract visitors and benefit from the large accessible tourist market.

3. Cities with a small ATM but a relevant tourist supply. The large cities at the ends of lines such as Seville or Valencia and even Madrid fit this profile. Although the ATM for one-day trip is not large, this is not a limitation, as these cities are too big and have too many amenities for a oneday visit. Unlike the cities in the first group, there is no risk of decrease in overnight stays.

4. Cities with poor accessibility and poor tourist supply. In comparison with the other cities, they should not have overly high expectations regarding the utility of HSR for one-day tourism. However, HSR still improves their accessibility.

Based on homogeneous assumptions, the methodology is nonetheless useful for comparing situations created by the high-speed train in the various cities in the network and for identifying the winners and the losers of HSR. The comparison of these utility indicators for other travel purposes (e.g., business) or durations (e.g., weekend trips) would complete the analysis of HSR utility. Finally, the time available at a destination could easily be used to optimize timetables and transfer possibilities throughout the entire network, in combination with timetable optimization of the separated lines [40]. The methodology may also be useful in assessing the implications in terms of utility and efficiency of the new by-passes, network extensions (i.e., the line between Barcelona and the French border) or even, in the future, the entire European network.

Acknowledgements This study was supported by a grant from the UE FEDER Funds and the Ministry of Science and Innovation (Grant N TRA2011-28465-C03-01).

\section{References}

1. Ureña JM, Menéndez JM, Guirao B, et al (2005) High speed railway and metropolitan integration in Spain: the case of Ciudad Real and Puertollano. Eure-Revista Latinoamericana de Estudios Urbano Regionales 31(92): 87-104.

2. Menerault P, Barré A (2005) El TGV y la reorganizacion de los transportes ferroviarios en la región de Nord-Pas-de-Calais. Ingeniería y Territorio 70: 28-33.

3. Jong M (2007) Attractiveness of HST Locations: Eight Cases in Northwest Europe. Master Thesis Urban Planning, Universiteit van Amsterdam, Amsterdam, $251 \mathrm{p}$.

4. Fröidh O (2005) Market effects of regional high-speed trains on the Svealand line. Journal of Transport Geography 13: 352-361.

5. Coronado JM (2007) Redes regionales de Alta Velocidad en España. In: Ribalaygua C, Alta Velocidad y Territorio. Universidad de Castilla La Mancha, Ciudad Real, pp. 61-70.

6. Dobruszkes F (2011) High-speed rail and air transport competition in Western Europe: A supply-oriented perspective. Transport Policy 18(6): 870-879.

7. Ureña JM, Menerault P, Garmendia M (2009) The high-speed rail challenge for big intermediate cities: A national, regional and local perspective. Cities 26(5): 266-279.

8. Chen C, Hall P (2010) The Impacts of High-Speed Trains on British Economic Geography: A Study of the UK's IC125/225 and its Effects. Journal of Transport Geography 19: 689-704.

9. Ureña JM, Ribalaygua C, Coronado JM, et al (2006) Situaciones y retos territoriales de la Alta Velocidad Ferroviaria en España. Ciudad y Territorio - Estudios Territoriales 38: 397-424.

10. Bellet C (2010) Nuevas tecnologías de transporte y metropolitanización discontínua del territorio. El Tren de Alta Velocidad en Segovia. ACE - Arquitectura, Ciudad y Entorno 4(12): 26-42.

11. Garmendia M, Ureña JM, Ribalaygua C, et al (2008) Urban residential development in isolated small cities that are partially integrated in metropolitan areas by High Speed Train. European Urban and Regional Studies 15(3): 249-264.

12. Garmendia M, Ureña JM, Ribalaygua C (2012) HSR implications for cities. Cities 29: 26-31.

13. Martínez HS, Givoni M (2011) The accessibility impact of a new High-Speed Rail line in the UK - a preliminary analysis of winners and losers. Journal of Transport Geography, In press.

14. Offner JM (1993) Les effets structurants du transport : mythe politique, mystification scientifique, L'Espace Geographique 3: 233-242.

15. Gutiérrez J (2001) Location, economic potential and daily accessibility: an analysis of the accessibility impact of the high-speed line Madrid-Barcelona-French border. Journal of Transport Geography 9: 229-242.

16. Ortega E, López E, Monzón A (2011) Territorial cohesion impacts of high-speed rail at different planning levels. Journal of Transport Geography 24: 130-141.

17. Hägerstrand $T$ (1970) What about people in regional science? Papers of the Regional Science Association 24(1): 7-21.

18. Törnqvist G (1970) Contact systems and regional development. The Royal University of Lund, 1970. 
19. Erlandsson U (1979) Contact potentials in the European system of cities. In: Folmer H. (Ed) Spatial inequalities and regional development, Regional Science Symposium, Martinus Nijhoff Publishing, pp 93-116.

20. Gutiérrez J (1991) Indicadores de accesibilidad en transporte público en el medio rural: Una propuesta metodológica. Estudios geográficos 52(203): 205-222.

21. L'Hostis A, Baptiste H (2006) A transport network for a City network in the Nord-Pas-de-Calais region: linking the performance of the public transport service with the perspectives of a monocentric or a polycentric urban system. European Journal of Spatial Development 20.

22. Davezies L, Lejoux P (2003) Un train peut en cacher un autre. Derrière l'économie productive, attention à l'économie présentielle. XXXIX ${ }^{\mathrm{e}}$ Colloque ASRDLF, 1-3 Lyon, 2003.

23. Lejoux P (2009) De l'économie touristique à l'économie présentielle : le cas des régions et des départements français. ESSACHESS - Journal for Communication Studies 9: 11-28.

24. Menéndez JM, Coronado JM, Rivas A (2002) Incidencias socioeconómicas y territoriales derivadas de la construcción en ciudades de tamaño pequeño: el caso de Ciudad Real y de Puertollano. Estudios de Construcción y Transportes 94: 29-54.

25. Van den Berg L, Pol P (1998) The European high-speed train and urban development. Experiences in fourteen European urban regions. Ashgate, Aldershot, $274 \mathrm{p}$.

26. La Rocca RA (2008) Alta Velocità e attrattività turistica del territorio. Territorio Mobilità e Ambiente - TeMALab 1(1): 71-80.

27. Alonso MP, Bellet C (2009) El tren de Alta Velocidad y el proyecto urbano: Un nuevo ferrocarril para la Zaragoza del tercer milenio. Scripta Nova: Revista Electrónica de Geografía y Ciencias sociales 13(281).

28. Masson S, Petiot R (2009) Can the high speed rail reinforce tourism attractiveness? The case of the high speed rail between Perpignan (France) and Barcelona (Spain). Technovation 29(9): 611-617.

29. Ureña JM (2002) El impacto regional de la línea de alta velocidad Madrid-Sevilla: provincias de Córdoba y Ciudad Real. Economía Aragonesa 2(19): 67-75.
30. Serrano R, Garmendia M, Coronado JM, et al (2006) Análisis de las consecuencias territoriales del AVE en ciudades pequeñas: Ciudad Real y Puertollano. Estudios Geográficos 67(260): 199-229.

31. Bazin S, Beckerich C, Delaplace M, et al (2011) Grande vitesse ferroviaire et développement économique local : une revue de la littérature. Recherche Transports Sécurité 27(3) : 215-238.

32. Guirao B, Soler F, González N, et al (2008) Análisis de los impactos generados por la nueva línea de alta velocidad Madrid-Toledo sobre la demanda de transporte. Estudios de construcción y transportes 108: 111-133.

33. Molina C, Martín-Consuegra D, Esteban A, Díaz E (2007) Segmentación de la demanda turística: un análisis aplicado a un destino de turismo cultural, Revista de Análisis Turístico 4: $36-48$.

34. Hinojosa V (2012) Avexperience, 18 ciudades a golpe de AVE. Hosteltur 215: 42.

35. Laird J, Nellthorp J, Mackie P (2005) Network effects and total economic impact in transport appraisal. Transport Policy 12: 537544.

36. Neutens T, Schwanen T, Witlox F (2011) The prism of everyday life: towards a new research agenda for time geography. Transport Reviews 31(1): 25-47.

37. ESPON (2010) FOCI-Future Orientations for Cities. Final Report, $63 \mathrm{pp}$. http://www.espon.eu/main/Menu_Projects/Menu_ AppliedResearch/foci.html

38. Román C, Espino R, Martín JC (2007) Competition of high-speed train with air transport: The case of Madrid-Barcelona. Journal of Air Transport Management 13: 277-284.

39. Ureña JM, Coronado JM, Garmendia M, Romero V (2012) Territorial implications at national and regional scales of high-speed rail. In: Ureña J.M, Territorial Implications of High Speed Rail: A Spanish Perspective. Ahsgate, London, pp. 129-162.

40. Castillo E, Gallego I, Ureña JM, Coronado JM (2011) Timetabling optimization of a mixed double- and singletracked railway network. Applied Mathematical Modelling 35(2): 859-878. 